\title{
Seasonal Micrometeorological Changes over a Grassland in Inner Mongolia
}

\author{
Yoshinobu HARAZONO*, Li Schenggong** SHEN Janyou**, and He Zhongyin** \\ (* National Institute of Agro-Environmental Sciences, Kannondai, Tsukuba, 305, Japan) \\ (** The Institute of Desert Research, Academia SINICA, Lanzhou, China, 730000)
}

\begin{abstract}
Field observations were carried out over grasslands facing desertification in a semi-arid area in China, then the micrometeorology was examined in relation to desertification. Albedo changed with grass growth, which reflects the surface conditions. Wind profile over the grass was logarithmic though over the dune a turbulent mixing layer which prevents plant growth was dominant. Evapotranspiration of the grassland ET was $2.8 \mathrm{~mm} /$ day in early August, while it was less than $1 \mathrm{~mm} /$ day in the dry season. Heat budget of the grassland facing desertification was close to that of the dune.
\end{abstract}

Key words: desertification, dune, heat budget, grassland, micrometeorology

\section{Introduction}

Most grasslands in semi-arid areas are currently facing a crisis of desertification which has been brought on not only by climatic change but also by human activities such as over grazing and poor field management (Biswas, 1978). As desertification is recognized as an important environmental problem on global scale (Wolman and Fouriner, 1987), a comprehensive investigation to elucidate the mechanism of desertification is demanded.

This study focused on the role of the plant community on the mechanism of desertification in semi-arid areas. Plant communities have their own specific ecosystem, and the progression of desertification is destroying their unique micrometeorological characteristics, thus enhancing the decay of the community. However, there is not much information on the micrometeorology of the plant community facing desertification. In this study, the interaction between the plant community and micrometeorology in relation to desertification was examined by field measurements at a semi-arid area in China. The field measurements were carried out in Inner Mongolia from October 1990, in accordance with the Japan-China joint study project by STA.

\section{Location and method of measurements.} 2.1. Climatic characteristics at the measurement sites

Micrometeorological measurements were carried out from mid May to the end of September 1991 at Naiman which is semi-arid, containing grasslands, dunes, and a few forests, which are facing desertification.

Fig. 1 shows the ten-year average temperature, precipitation, and evaporation in Naiman. Most precipitation occurs during the rainy season from June to August, and after that the dry season begins. However, evaporation reaches high levels in April, May and June, with the solar radiation during those months being at lower

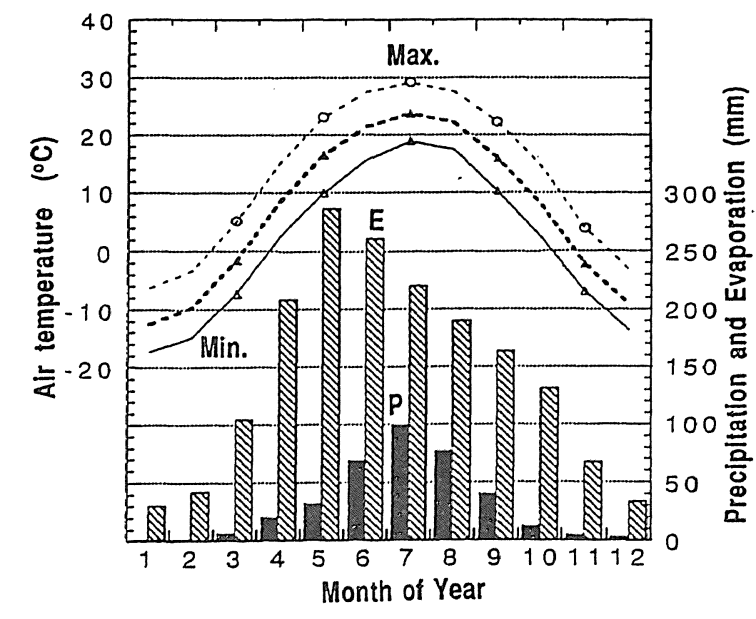

Fig. 1 Seasonal variations of precipitation, evaporation and air temperature (maximum, mean, minimum) at the measurement site in Inner Mongolia, China. 
levels than July and August. These high levels of evaporation was caused by dry and strong north west wind, and then by sensible heat changes into latent heat which finally exceeded the level of net radiation. Air temperature in winter is too low to grow plants, then the plant growing season is during late April and end September.

\subsection{Methods of measurement and analysis}

Over the grassland, heat budgets and wind profiles were measured using masts. Measurements over a dune and vegetation were also carried out for comparison.

Wind profiles up to $5 \mathrm{~m}$ in height and the wind direction were measured by cup anemometers and a wind vane (Makino, AF750, VF16), respectively. Gradients of air temperature and humidity were obtained by ventilated psychrometers at two heights. Net radiation was measured by a net radiometer (Eko, CN11), and solar radiation and its reflection were measured by pyranometer (Iio, SR2) over the grass and dune, respectively. Soil temperature and soil heat flux were also measured by thermocouples and heat flow plates (Eko, CN9), respectively. Data were sampled every minute by a data logger (North Hightech, IDL3200). Measurements were carried out 5 times from May to September, in 1991 and each set of measurements was continued for 3 days.

Latent heat $(l E)$ and sensible heat $(H)$ were evaluated by both the gradient method and the heat budget method, and the former was mainly used for nocturnal variations of $l E$ and $H$, and the latter for diurnal variations. Atmospheric stability and the log law of wind profiles were used for correction of diffusion velocity according to Thom (1975) in unstable conditions, but were not corrected under stable conditions.

\section{Results and discussion}

\subsection{Changes of albedo over grassland}

Fig. 2 shows albedo differences in the grassland from May to September. The albedo of the grassland was 0.25 in mid May and then decreased to 0.20 with the growth of grass. After June, the grass didn't develope much, and albedo kept a constant value.

In August, albedo of the vegetated site, grassland, and dune were 0.34, 0.20, 0.14, respectively. These differences which affect the heat and water budget of different levels of desertification in semi-arid areas are caused by differences in the surface conditions and soil water conditions. Therefore, the albedo data are available for remote sensing analysis to evaluate the vegetation growth and water conditions in areas facing desertification.

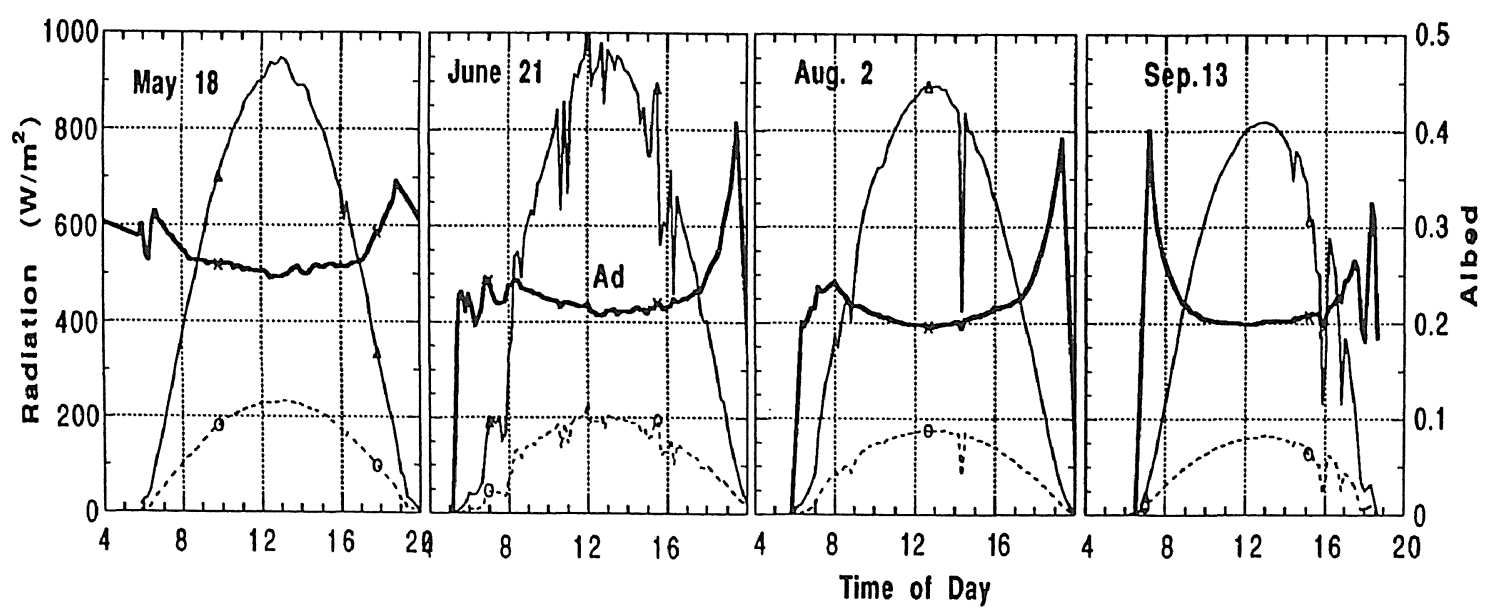

Fig. 2 Seasonal changes of albedo over a grassland in Inner Mongolia. 


\subsection{Wind profiles}

Fig. 3 shows the changes of normalized wind profiles with the growth of grass. The wind profiles over the grassland were logarithmic all day long during measurement periods, while those over the dune weren't logarithmic but were a mixing layer in the daytime (Harazono et al., 1992), as shown in Fig. 3. The friction stress which was in inverse proportion to the gradient of the wind profile increased with grass growth from May to September. This shows that grass absorbs wind stress and prevents sand jumping away. On the other hand, over the dune, wind speed just above the ground surface was high, which puts

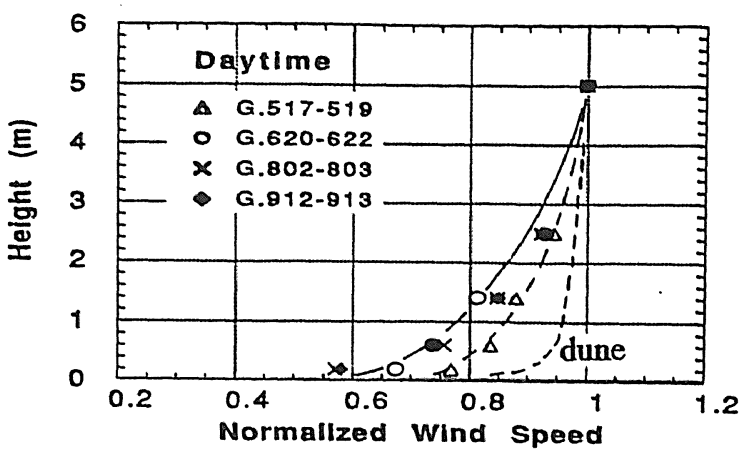

Fig. 3 Normalized wind profiles over the grassland and dune in the daytime. strong wind pressure on plants and ground surface, thus letting sand jump away and prevent the plant growth. If the grassland is destroyed once, the changed micrometeorology prevents the recovery of grass and then controlling the wind profile using a kind of windbreak is recommended for recovering and maintaining the grass.

\subsection{Heat budget over the grassland}

Daily variations of heat budget components from May to September are shown in Fig. 4. Precipitation for 5 days before measurement were $13 \mathrm{~mm}$ for May, $10 \mathrm{~mm}$ for June, $63 \mathrm{~mm}$ for August, and $2 \mathrm{~mm}$ for September, respectively.

Diurnal maximum net radiation $R n$ was $500 \mathrm{~W} / \mathrm{m}^{2}$ in May and September, and more than $600 \mathrm{~W} / \mathrm{m}^{2}$ in mid June and August. Most of $R n$ was used for evapotranspiration, and maximum latent heat $l E$ was $350 \mathrm{~W} / \mathrm{m}^{2}$ in mid June which is equivalent to $0.5 \mathrm{~mm} / \mathrm{h}$ of evapotranspiration. In September, the dry season, $l E$ was almost same as those in the morning, while in the afternoon it decreased rapidly and the share of sensible heat $H$ was larger than other seasons, which reflects the low level of soil water contents in grassland in the dry season.

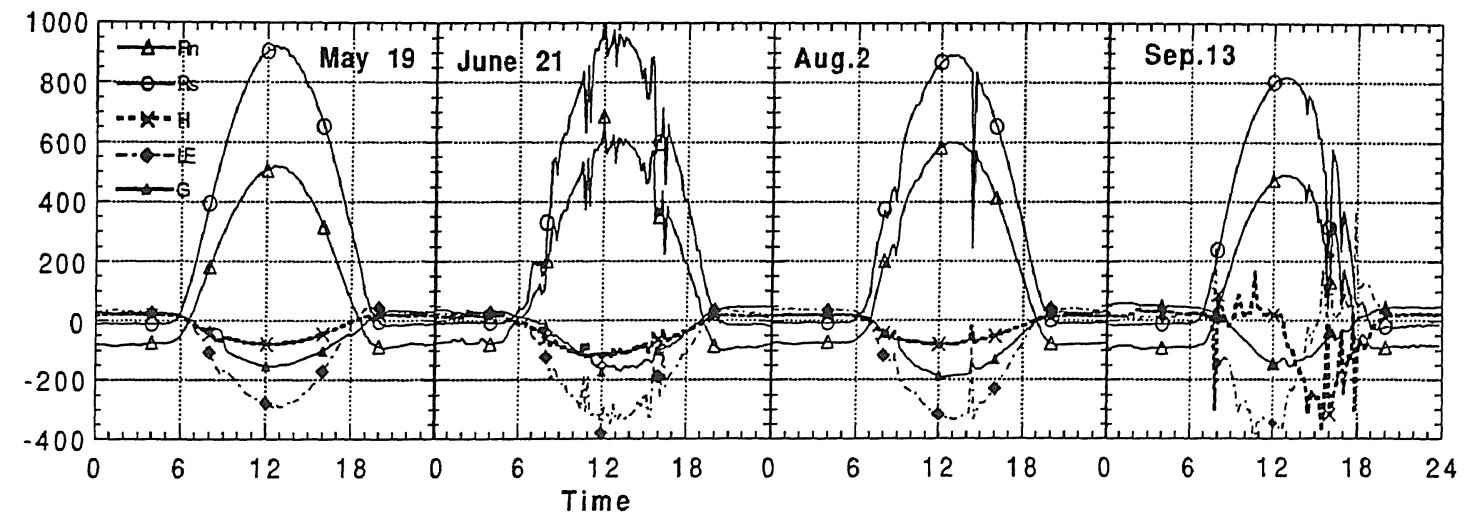

Fig. 4 Seasonal changes in the daily variation of heat budget components over the grassland.

Table 1 shows the seasonal changes in the daily amounts and shares of heat budget over the grassland. The share of $l E$ was highest in June, and this decreased with grass growth and maturation. The maximum daily evapotranspiration was $2.8 \mathrm{~mm}$ obtained in early August, just after the rainy season when the plant biomass was at its maximum level, while it was less than 1 $\mathrm{mm}$ in the dry season. Both Fig. 1 and Table 1 show that the evapotranspiration of the grassland was independent of the atmospheric moisture deficit and was dependant on the plant activity and 
soil water level. The share of $H$ increased with the season instead of decreases of $G$ and $l E$.

\subsection{Comparison of heat budget among the three sites}

Table 2 shows the comparison of heat budget components in early August for three different surface conditions in the semi-arid area in China. $R n$ at vegetation was 1.7 times that at the dune due to high reflection of solar radiation $R s$, and $l E$ at the vegetation was almost twice that of the grassland. At night-time $G$ was almost the same in the three sites, while at the dune and grassland $l E$ it was larger which compensated for the large $R n$. From this table the characteristics of the heat budget of grasslands facing desertification was more similar to that of the dune than the vegetation.

\section{Conclusion}

1) Albedo of the grassland decreased from 0.25 in mid May to 0.2 after June, which reflects the surface conditions.

2) Wind profile was logarithmic over grass, while the turbulent mixing layer was dominant over the dune, which prevents plant growth.

3) Maximum evapotranspiration $E T$ was $2.8 \mathrm{~mm} /$ day in early August, while it was less than $1 \mathrm{~mm} /$ day in the dry season. ET was dependent on plant conditions more than atmospheric conditions.

4) Heat budget of the grassland facing desertification was close to that of dune.

\section{References}

Biswas, M.R., 1978 : UN Conference on desertification, in prospect. Environ, Conserve., 5, 247-262.

Harazono, Y., Shen, J., Liu, S., and Li, S., 1992 : Micrometeorological characteristics of a sand dune in the eastern part of inner Mongolia, China in Autumn. J. Agr. Met., 47, 217-224. 16, 1-14.

Thom, A.S., 1975; Momentum, mass and heat exchange of plant communities, in Vegetation and Atmosphere. ed by Monteith, J.L., Academic Press, London, 57-110.

Wolman, M.G. and Fournier, F.G.A., eds, 1987 : Land transformation in Agriculture. Scope 32, John Wiley, Sussex, 531p.
Table 1 Seasonal changes of heat budget components and their shares over the grassland in 1991.

\begin{tabular}{|c|c|c|c|c|c|c|c|}
\hline & \multicolumn{3}{|c|}{$(\mathrm{MJ} / \mathrm{m} 2)$} & \multirow[b]{2}{*}{ G } & \multicolumn{3}{|c|}{ Relative Value } \\
\hline & $\mathrm{Rn}$ & $\mathrm{H}$ & IE & & $\mathrm{H}$ & $\mathrm{IE}$ & G \\
\hline 17-May & 8.44 & -1.51 & -4.22 & -2.71 & 0.18 & 0.50 & 0.32 \\
\hline 21 -Jun & 10.31 & -2.1 & -5.75 & -2.46 & 0.20 & 0.56 & 0.24 \\
\hline 2-Aug & 15.91 & -4.06 & -6.95 & -4.9 & 0.26 & 0.44 & 0.31 \\
\hline 19-Aug & 9.55 & -4.54 & -2.77 & -2.24 & 0.48 & 0.29 & 0.23 \\
\hline 13-Sep & 9.19 & -4.9 & -2.48 & -1.81 & 0.53 & 0.27 & 0.20 \\
\hline
\end{tabular}

Table 2 Differences in heat budget components $\left(\mathrm{kJ} / \mathrm{m}^{2}\right)$ and their shares (\% in parenthesis) among three different sites in a semi-arid area (1991-summer).

\begin{tabular}{lccccc}
\hline Daytime & & $\mathrm{Rn}$ & $\mathrm{H}$ & $\mathrm{G}$ & $\mathbb{E}$ \\
\cline { 3 - 6 } Vegetation & 17949.8 & -5308.2 & -1366.6 & -11275.3 \\
& $(100)$ & $(-29.6)$ & $(-7.6)$ & $(-62.8)$ \\
Grassland & 15905.8 & -4055.5 & -4897.4 & -6954.1 \\
& $(100)$ & $(-25.5)$ & $(-30.8)$ & $(-43.7)$ \\
Dune & 10764.1 & -4155.1 & -2574.0 & -4034.2 \\
& $(100)$ & $(-38.6)$ & $(-23.9)$ & $(-37.5)$ \\
\hline \multirow{2}{*}{ Night time } & $\mathrm{Rn}$ & $\mathrm{H}$ & $\mathrm{G}$ & $\mathbb{E}$ \\
\cline { 2 - 6 } Vegetation & -1786.3 & 697.9 & 980.8 & 107.5 \\
& $(100)$ & $(-39.1)$ & $(-54.9)$ & $(-6.0)$ \\
Grassland & -2646.8 & 416.9 & 994.7 & 1234.7 \\
& $(100)$ & $(-15.8)$ & $(-37.6)$ & $(-46.6)$ \\
Dune & -1998.9 & 127.5 & 962.5 & 909.0 \\
& $(100)$ & $(-6.4)$ & $(-48.2)$ & $(-45.5)$ \\
\hline
\end{tabular}

